
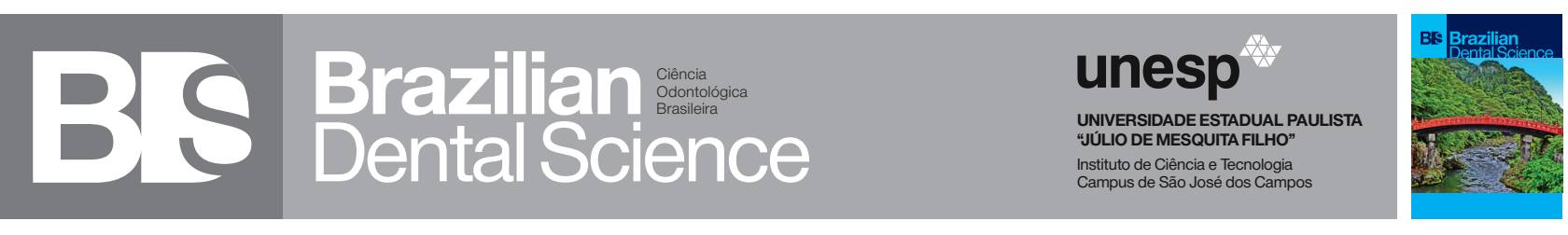

\title{
Non-thermal plasma increase bond strength of zirconia to a resin cement
}

\author{
Plasma não-térmico aumenta a resistência de união da zircônia a um cimento resinoso
}

Beatriz Togoro Ferreira da SILVA ${ }^{1}$, Lívia Tosi TREVELIN ${ }^{1}$, Fernanda de Sá TEIXEIRA², Maria Cecília SALVADORI ${ }^{2}$, Paulo Francisco CESAR $^{3}$, Adriana Bona MATOS ${ }^{1}$

1 - Operative Dentistry Department - School of Dentistry - University of São Paulo - Sao Paulo - Brazil.

2 - Institute of Physics - University of São Paulo - Sao Paulo - Brazil.

3 - Biomaterials and Oral Biology Department - School of Dentistry - University of São Paulo - Sao Paulo - Brazil.

\begin{abstract}
Objective: This study investigated the influence of different surface treatments on zirconia surface energy, roughness and microshear bond strength. Material and Methods: Forty eight slices of Yttriastabilized tetragonal zirconia polycrystal (Y-TZPVITA In-Ceram $\AA$ YZ for inLab $®)(6.4$ x 3.2 x 1.6 $\mathrm{mm}$ ) were divided into 3 groups according to the surface treatment $(n=16)$ :YTZP_control -untreated; YTZP_plasma -surface treatment with non-thermal oxygen plasma; YTZP_primer - coating with ceramic primer. Surface energy $(n=6)$ was measured with a goniometer; and surface roughness $(n=10)$ was analyzed with a 3D profilometer were performed over zirconia surface. On the same specimens of surface roughness, on the treated zirconia's surface, resin cement (PANAVIA V5 - Kuraray Noritake Dental) was built up by inserting the resin cement into Tygon tubes ( $1 \mathrm{~mm}$ of internal diameter X 1 $\mathrm{mm}$ length). After $24 \mathrm{~h}$ storage, microshear test was assessed. Data were analyzed by one-way ANOVA and Tukey posthoc test ( $\mathrm{p}<0.05)$. Results: Nonthermal oxygen plasma treated specimens exhibited higher statistically significant surface energy ( $\mathrm{p}=$ $0.00)$ and bond strength $(\mathrm{p}=0.00)$ when compared to control and primer groups. Roughness test ( $\mathrm{p}=$ 0.897) could not detect statistical difference among the tested groups. Conclusion: Non-thermal oxygen plasma should be a suitable alternative for zirconia surface treatment prior to luting hence it improved microshear bond strength and provided higher surface energy without affecting surface roughness.
\end{abstract}

\section{KEYWORDS}

Adhesion; Non-thermal plasma; Surface treatment.

\section{RESUIMO}

Objetivo: Este estudo investigou a influência de diferentes tratamentos de superfície na energia de superfície, rugosidade e resistência de união da zircônia. Material e Métodos: Quarenta e oito fatias de zircônia tetragonal policristalina estabilizada por ítria (Y-TZP - VITA InCeram® YZ for inLab®) $(6,4$ x 3,2 x 1,6 mm) foram divididas em 3 grupos de acordo com o tratamento de superfície ( $\mathrm{n}=16$ ): YTZP_controle sem tratamento; YTZP plasma - tratamento de superfície com plasma de oxigênio não térmico; YTZP_primer - aplicação de um primer cerâmico. A energia da superfície $(n=6)$ foi medida com o auxilio de um goniômetro; e a rugosidade superficial $(\mathrm{n}=10)$ foi analisada com um perfilômetro 3D. Nos mesmos espécimes da rugosidade, prolongamentos de cimento resinoso (PANAVIA V5 - Kuraray Noritake Dental) foram construídos inserindo o cimento em micro túbulos de silicone (1mm de diâmetro interno de X $1 \mathrm{~mm}$ de comprimento). $\mathrm{O}$ teste de microcisalhamento foi realizado após 24h. Os dados foram analisados estatisticamente ANOVA um fator e teste auxiliar de Tukey ( $p<0,05)$. Resultados: Os espécimes tratados com plasma de oxigênio apresentaram maiores valores de energia de superficie $(\mathrm{p}=0,00)$ e resistência de união estatisticamente significante $(p=0,00)$ quando comparados aos grupos controle e do primer. A análise de rugosidade ( $\mathrm{p}=$ 0,897) não detectou diferença estatística entre os grupos testados. Conclusão: O plasma não térmico pode ser uma alternativa para o tratamento de superfície de zircônia antes da cimentação, pois aumentou a resistência de união ao microcilsalhamento e proporcionou maior energia superficial sem afetar a rugosidade da superfície.

\section{PALAVRAS-CHAVE}

Adesão; Plasma não-térmico; Tratamento de Superfície 


\section{INTRODUCTION}

Tr hei he increased aesthetic demand for prosthetic treatments have led to the development of high-strength ceramic materials, such as yttrium-stabilized tetragonal zirconia polycrystals (Y-TZP), which has widened the indications of metal-free restorations. Y-TZP has higher mechanical properties, such as, flexural strength, compression and abrasion resistance, when compared to feldspathic ceramics and glass ceramics [1] due to its polycrystalline nature and the lack of a glassy phase in its microstructure. In addition, this material is toughened by a phase transformation mechanism, in which the tetragonal crystals are transformed into monoclinic whenever stresses concentrate in the surrounding of a crack tip. Since the monoclinic crystal has 3-5\% higher volume than that of the tetragonal crystal, this phase transformation creates a significant level of compressive stresses around the preexisting flaw, hindering crack propagation and subsequent catastrophic failure $[2,3]$.

Despite the superior mechanical properties of Y-TZP, its cementation on tooth preparations remains a challenging task, due to its inability to be etched by the classic hydrofluoric acid pretreatment [4]. Additionally, Y-TZP does not contain silica in its composition impairing the adhesion with silane agent [5]. Such an inert surface results in poor adhesion between resin cements and Y-TZP [6].

Alternative methods for conditioning the surface of Y-TZP crowns prior luting have been suggested in the literature, such as aluminum oxide sandblasting and tribochemical silica coating $[2,7]$. The latter has been regarded as the preferred method for zirconia surface treatment, based on the bond strength literature [7-10]. However, there is also scientific evidence indicating that sandblasting creates critical defects on the ceramic surface which might become crack initiators and compromise the longterm performance of the zirconia restoration $[11,12]$. Primers containing the 10-MDP monomer (10-methacryloyloxydecyldihydrogen phosphate) have claimed to create a chemical interaction between crystalline ceramics and resin cements that improved adhesion $[13,14]$. Other studies suggested the use of high power lasers for alter the surface of Y-TZP $[15,16]$. However studies have demonstrated lower bond strength after aging [9]. Controversial literature are observed due to the diversity parameters and methodologies tested. For this reason, alternative strategies to improve bond strength to zirconia should be explored.

Non-thermal plasma (NTP) has been used as a surface treatment that is able to modify the surface chemistry without damaging glass ceramics [17] and zirconia [18]. Plasmas are ionized gases containing a mixture of electrons, ions, and free radicals that can induce chemical reactions resulting in significant changes on the functional groups of material surface [19]. Such a surface treatment is capable of transforming non-reactive surfaces into reactive ones without affecting their mechanical properties [20]. In this way, plasma application enhances surface energy (SE) and wettability of substrates $[17,18,20-25]$, improving the adhesion of the treated surface to Rely X U200 [23], Panavia F 2.0 [23], Rely X Unicem [26] and Clearfil Esthetic [27] resin cements.

An important advantage of plasma application as a surface treatment is the fact that it does not remove material structure and does not deposit a pellicle on the cementation surface; therefore, the adaptation of the zirconia crown is not compromised [18,26]. NTP is an alternative surface treatment that needs to be explored, especially when a new formula of conventional-type adhesive resin cement is introduced in the market.

Panavia V5 (Kuraray Noritake Dental, Tokyo, Japan) is an amine-free resin cement composed of methacrylate monomers, new redox initiators, and fillers. The material system consists of a dual-curing resin cement and a one-bottle MDP-based self-etching primer which 
enables improvement in bond compatibility and long-term color stability [28]. The novelty of Panavia V5 (PV5) is to simplify a conventional adhesive cement system, combining easy handling, by using a single bottle primer without previous etching, as well as being automix version [28,29]. The incorporation of a self-etch component and a multi-step adhesive into a single cement system reduces technique-sensitivity and facilitates daily clinic routines. No other study was detected in literature that suggest NTP surface treatment as a non-destructive method to effectively enhance the bond strength of a new formulation of a resin cement (Panavia V5) to Y-TZP surfaces.

Therefore, the aim of this study was to evaluate the effect of non-thermal oxygen plasma surface treatment on the surface energy, roughness and bond strength of zirconia. The null hypotheses were outlined: (1) NTP surface treatment does not increase surface energy of zirconia; (2) NTP surface treatment does not increase roughness of zirconia and; (3) NTP surface treatment does not increase microshear bond strength of a resin cement to zirconia.

\section{MATERIALS AND METHODS}

\subsection{Specimen preparation}

The materials used in the present study are listed in Table 1. A commercial Y-TZP polycrystalline material (VITA In-Ceram ${ }^{\circledR}$ YZ for inLab®; VITA Zahnfabrik, Bad Säckingen, Germany) was cut from unsintered blocks using a low-speed cutting machine (Isomet 1000 Precision Saw; Buehler Ltd, Lake Bluff, IL, USA) under water-cooling at 250 (rpm) to obtain 48 specimens with dimensions $8 \times 4 \mathrm{x}$ $2 \mathrm{~mm}$.
Table 1 - Materials used in this study with their application procedure

\begin{tabular}{|c|c|c|}
\hline Material & Composition & Application procedure \\
\hline $\begin{array}{l}\text { Y-TZP blo- } \\
\text { cks } \\
\text { VITA In-Ce- } \\
\text { ram YZ for } \\
\text { inLab }\end{array}$ & $\begin{array}{l}92 \% \mathrm{ZrO}, 5 \% \\
\text { Y2O3, } \mathrm{HfO} 13 \% \text {, and Al2O3, } \\
\text { Si0211\% by weight }\end{array}$ & - \\
\hline $\begin{array}{l}\text { PANAVIA V5 } \\
\text { (PV5) } \\
\text { Kuraray } \\
\text { Noritake }\end{array}$ & $\begin{array}{l}\text { Paste A: Bis-GMA, TEGD- } \\
\text { MA, hydrophobic aromatic } \\
\text { dimethacrylate, hydrophilic } \\
\text { aliphatic dimethacrylate, } \\
\text { initiators, accelerators, } \\
\text { silanated barium glass filler, } \\
\text { silanated, fluoroalminosilica- } \\
\text { te glass filler, colloidal silica } \\
\text { Paste B: Bis-GMA, hydropho- } \\
\text { bic aromatic dimethacrylate, } \\
\text { hydrophilic aliphatic dime- } \\
\text { thacrylate, silanated barium } \\
\text { glass filler, silanated almi- } \\
\text { nium oxide filler, accelera- } \\
\text { tors, dl-camphorquinone, } \\
\text { pigments }\end{array}$ & $\begin{array}{l}\text { Cylinders were build up } \\
\text { on the zirconia surface, } \\
\text { by inserting it into tygon } \\
\text { tubes and then light cure } \\
\text { for } 40 \mathrm{~s}\end{array}$ \\
\hline $\begin{array}{l}\text { Clearfil } \\
\text { Ceramic } \\
\text { Primer } \\
\text { Kuraray } \\
\text { Noritake }\end{array}$ & $\begin{array}{l}\text { 3-Methacryloxypropil trime- } \\
\text { thoxy silane, } 10 \text {-MDP }\end{array}$ & $\begin{array}{l}\text { Apply on the zirconia } \\
\text { surface for } 15 \mathrm{~s} \text { and air- } \\
\text { dry gently }\end{array}$ \\
\hline
\end{tabular}

Bis-GMA: bisphenol A diglycidyl ether dimethacrylate, TEGDMA: triethyleneglycol dimethacrylate,10-MDP: 10-methacryloyloxydecyl dihydrogen phosphate

Afterwards, the specimenswere ultrasonically (Digital Ultrasonic Cleaner; Shenzhen Codyson Electrical Co., Ltd, Shenzhen, China) cleaned in distilled water and dried with absorbent paper (Mellita; Mellita do Brasil LTDA, Guaiba, Brazil) ; and were sintered in a furnace (VITA ZYrcomat; VITA Zahnfabrik, Bad Säckingen, Germany) at $1.530{ }^{\circ} \mathrm{C}$ for $7.5 \mathrm{~h}$ according to the manufacturer's instructions. After sintering, the specimens with dimensions of $6.4 \times 3.2 \times 1.6 \mathrm{~mm}$ were ultrasonically cleaned with $96 \%$ isopropanol for $3 \mathrm{~min}$.

The specimens were randomly assigned to three groups according to the surface treatment (Table 2): untreated (YTZP_control); with oxygen plasma (YTZP_plasma); and with ceramic primer (YTZP_primer). Zirconia specimens were tested 
in its surface energy $(n=6)$; roughness, by a $3 \mathrm{D}$ optical profilometry $(\mathrm{n}=10)$. On the same specimens of surface roughness, microshear bond strength ( $\mu \mathrm{SBS})(\mathrm{n}=10)$ was performed.

Table 2 - Experimental groups considering zirconia surface treatment as main factor $(n=16)$.

\begin{tabular}{|ll}
\hline Experimental Groups & \multicolumn{1}{c}{ Zirconia Surface Treatment } \\
\hline YTZP_control & \multicolumn{1}{c}{ Untreated - control } \\
\hline YTZP_plasma & $\begin{array}{l}\text { Non thermal oxygen plasma was applied } \\
\text { at } 120 \mathrm{~mm} \text { distance, for } 16 \text { min. }\end{array}$ \\
YTZP_primer & $\begin{array}{l}\text { Clearfil Ceramic Primer (Kuraray Noritake } \\
\text { Dental) was applied following the manu- } \\
\text { facturer's instructions }\end{array}$ \\
\hline
\end{tabular}

\section{group) \\ NTP surface treatment (YTZP_plasma}

A hollow-cathode plasma gun was used for the non-thermal oxygen plasma treatment of zirconia at a single point, covering the entire zirconia surface. The plasma equipment is made of ceramic, is stainless steel and aluminum construction, and the wire grid is a tungsten mesh. The plasma discharge occurs within the hollow cathode region, with the grounded tungsten mesh serving as anode. Oxygen gas, for the work described here, was coupled to the source through a small diameter plastic tube, using a needle valve to control the pressure. Samples were positioned $120 \mathrm{~mm}$ away from the plasma gun exit, which was fed with oxygen gas until the vacuum chamber has reached the base pressure of 2.0x10-4 mbar and set a voltage of 700 VDC to produce oxygen plasma stream [30]. A pilot study was done to determine the time point to increase the surface energy of zirconia. In this study, specimens were initially treated for 8 minutes; however low values of bond strength, as well as surface energy values, were observed. Based on this finding, we decided to increase the treatment time, applying $16 \mathrm{~min}$, which resulted in better effects on zirconia.

\section{Primer coating (YTZP_primer group)}

A commercially available ceramic primer, Clearfil Ceramic Primer (Kuraray Noritake Dental, Tokyo, Japan) (Table 1) was applied following the manufacturer's instructions; one layer of the primer was rubbed with a disposable brush tip for $15 \mathrm{~s}$; the excess of the solvent was evaporated with a gentle air stream for $5 \mathrm{~s}$.

\section{Analysis of Surface Energy (SE)}

The surface energy was evaluated under controlled temperature $\left(23 \pm 1^{\circ} \mathrm{C}\right)$ immediately after the surface treatments. Six specimens of each experimental group were used. The surface energy of the Y-TZP samples was measured with a goniometer CAM 200 (KSV instruments; LTD, Helsinki, Finland) by the sessile drop technique. Ten readings were made for each specimen to measure the deionized water contact angle (polar component), and another 10 readings were made to determine the ethylene glycol contact angle (dispersive component). At each reading, the samples were dried with absorbent paper (Mellita; Mellita do Brasil LTDA, Guaiba, Brazil). The distance from the tip, as well as the position of the samples, and the zirconia surface was kept constant form all assays. The relationship of the contact angle and surface energy was calculated by the Owens-WendtRabel-Kaelble method, which calculates the contact angle between drops of two liquids with different polarities and the Y-TZP surface [24,31].

\section{Analysis of surface roughness}

The average roughness ( $\mathrm{Ra}$ in $\mu \mathrm{m}$ ) of each specimen was measured using a non-contact profilometry (3D Proscan 2100; Scantron, Taunton, England). Three measurements with $1 \mathrm{x} 1 \mathrm{~mm}$ were made on different areas in the middle of the specimen. The equipment was set to go through 1000 steps in the X-axis, with each step measuring $0.001 \mathrm{~mm}$. In the Y-axis, there were 5 steps measuring $0.2 \mathrm{~mm}$ each. The roughness was measured from the average of 
Ra values in the $\mathrm{X}$-axis and $\mathrm{Y}$-axis, calculated by a Proscan Application software (Scantron; Taunton, England) version 2.0.17 [32].

\section{Bonding Procedure and $\mu$ SBS Test}

After $48 \mathrm{~h}$ completion of the surface treatment described above, $\mu$ SBS test was performed. Approximately 9 cylinders per zirconia block were mounted with Tygon tubing molds (R-3603; Norton Performance Plastic, Cleveland, USA) on treated zirconia surface, delimited by an adhesive tape [33]. Two hundred and seventy tygon cylinders with dimensions (1.0-mm internal diameter and 1.0$\mathrm{mm}$ thickness) were filled with Panavia V5 luting (Shade A3, Kuraray Noritake Dental, Tokyo, Japan). Subsequently, the cement excess was carefully removed with a blade and the cylinders were light-cured (Radii Plus; SDI Limited, Victoria, Australia) for $40 \mathrm{~s}$ (20 s from top and $20 \mathrm{~s}$ for bottom) with the irradiance of $500 \mathrm{~mW} /$ $\mathrm{cm}^{2}$, verified by the radiometer coupled to the light curing unit. Tygon tubes were carefully removed after $1 \mathrm{~h}$ of water storage with a scalpel blade. This is the first study which used $\mathrm{O}_{2}$ as the main component for plasma treatment with the new luting cement Panavia V5. Consequently, a short-term assayed is essential to analyze the performance of the new treatment. As a result, all the specimens were stored in distilled water at $37^{\circ} \mathrm{C}$ for $24 \mathrm{~h}$ before testing, which is classified as a standard for short-term storage in ISO/TR 11405. Samples were mounted in the jig a shear load was applied at the base of the resin cement cylinder by a thin wire $(0.20 \mathrm{~mm}$ diameter $)$ at a $1.0 \mathrm{~mm} / \mathrm{min}$ crosshead speed until failure in a Universal Testing Machine (Instron 5942 - Canton, Massachusetts, USA). Shear bond strengths in MPa were calculated by dividing the maximum force that induced failure by the bonded area.

\section{Analyses of Failure Mode}

The specimens were observed with a digital microscope (Dino-Lite Digital Microscope ${ }^{\circledR}$, AnMo Electronics Corp., New Taipei City, SanChung District, Taiwan) at 40x magnification for fracture pattern evaluation. The mode of failure was classified as follows: (a) cohesive: rupture in the cement; (b) mixed: when simultaneously exhibiting the zirconia surface and remnants of resin cement. Afterwards, the percentage of failed samples was calculated for each group.

\section{Statistical Analysis}

The statistical analyses were performed with Minitab 17 (Minitab 17, Minitab Inc, Pennsylvania, USA). A one-way ANOVA followed by Tukey's test ( $p=0.05$ ) was used in three distinct analyses to evaluated the surface roughness $(\mathrm{Ra})$, surface energy and bond strength.

\section{RESULTS}

Statistical significant differences among experimental groups for bond strength $(\mathrm{p}=0.00)$ and surface energy $(\mathrm{p}=0.00)$ were detected (Table 3), while for surface roughness, no statistical significant difference was observed among groups $(\mathrm{p}=0.897)$ (Table 3 and Figure 1).

Table 3 - Results of one-way ANOVA for surface roughness ( $p$ $=0.897)$, bond strength $(p=0.00)$ and surface energy $(p=0.00)$ tests in columns.

\begin{tabular}{|lccc|}
$\begin{array}{c}\text { Experimental } \\
\text { Groups }\end{array}$ & $\begin{array}{c}\text { Roughness } \\
\text { (Ra in } \mu \mathrm{m} \text { ) }\end{array}$ & $\begin{array}{c}\text { Bond strength } \\
\text { (in MPa) }\end{array}$ & $\begin{array}{c}\text { Surface energy } \\
\text { (in mN/m) }\end{array}$ \\
\hline YTZP_control & $0.99 \pm 0.19 \mathrm{a}$ & $17.85 \pm 3.71 \mathrm{~b}$ & $34.63 \pm 3.61 \mathrm{~b}$ \\
\hline YTZP_plasma & $1.01 \pm 0.31 \mathrm{a}$ & $24.70 \pm 4.10 \mathrm{a}$ & $62.34 \pm 5.53 \mathrm{a}$ \\
\hline YTZP_primer & $0.96 \pm 0.26 \mathrm{a}$ & $15.60 \pm 3.66 \mathrm{~b}$ & $35.73 \pm 1.14 \mathrm{~b}$ \\
\hline
\end{tabular}

* Different letters indicate statistical difference. 

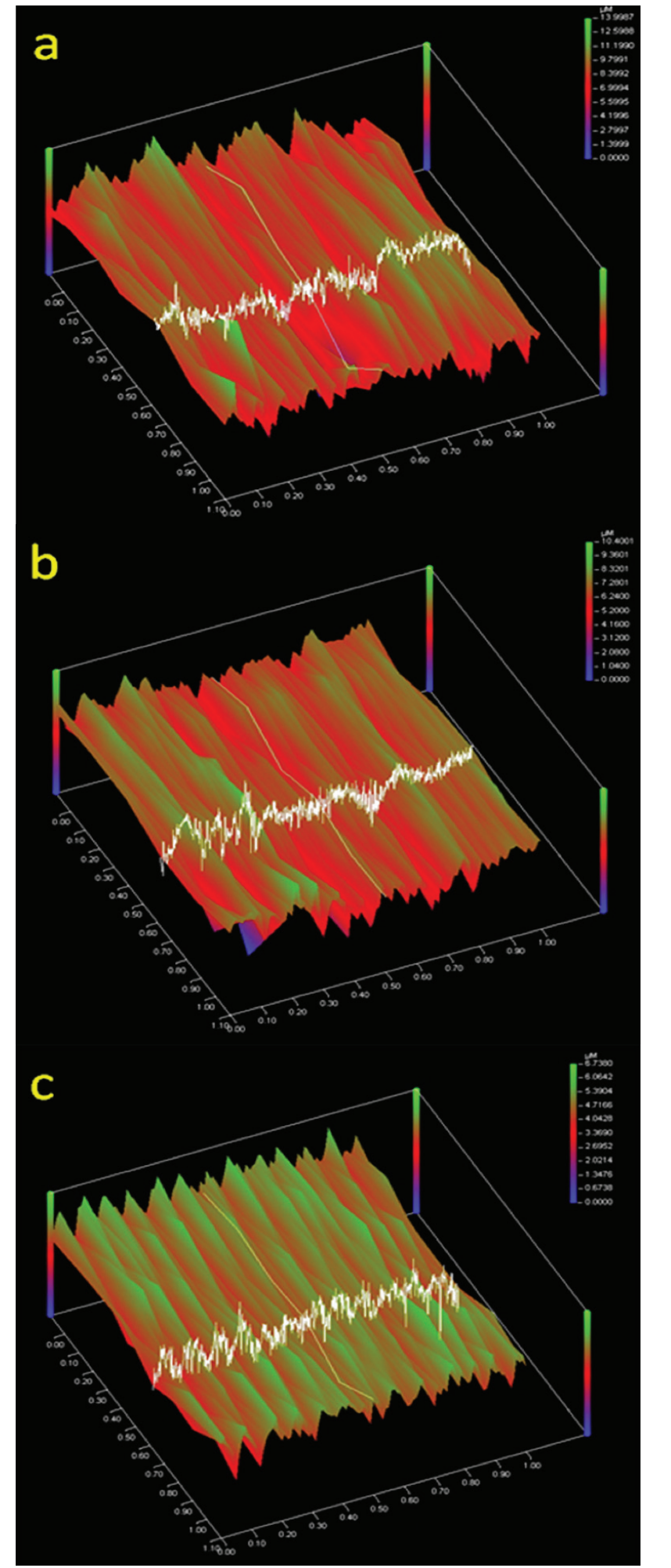

Figure 1 - Zirconia surface roughness obtained from noncontact optical profilometry (Proscan 2100) after surface treatments. a control group - untreated, b NTP treatment group, c primer application group.
Plasma treated surface exhibited the higher values $(24.7 \pm 4.10 \mathrm{MPa})$ and $(62.34 \pm 5.53 \mathrm{mN} / \mathrm{m})$, for respectively bond strength and surface energy. As shown in Figure 2, after NTP treatment, the polar component of Y-TZP increased. On the other hand, no statistically significant difference was detected when the control and the primer group were compared for both bond strength and surface energy tests. Figure 3 represents images of the contact angle readings using water and ethylene glycol for SE calculations before and after NTP and primer treatment.

The failure pattern was recorded in percentage (Table 4).

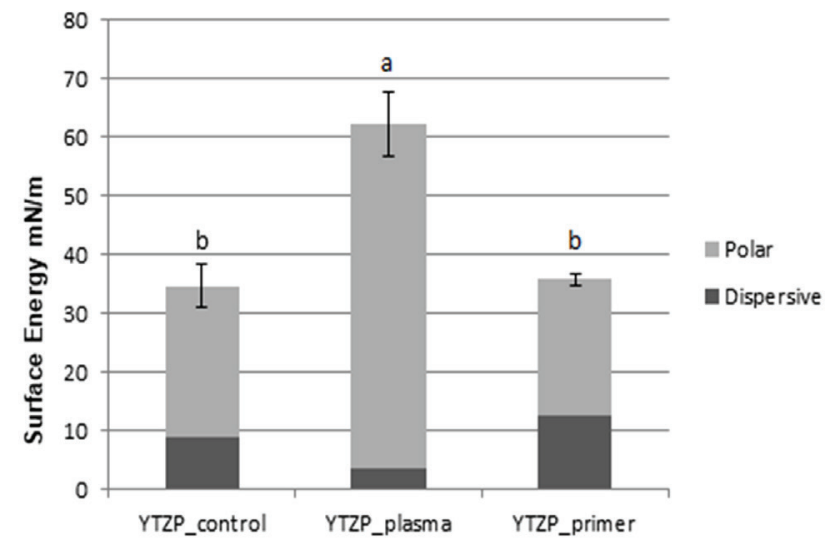

Figure 2 - Main polar and dispersive components of the experimental groups. The different lower case letters represent significant differences.

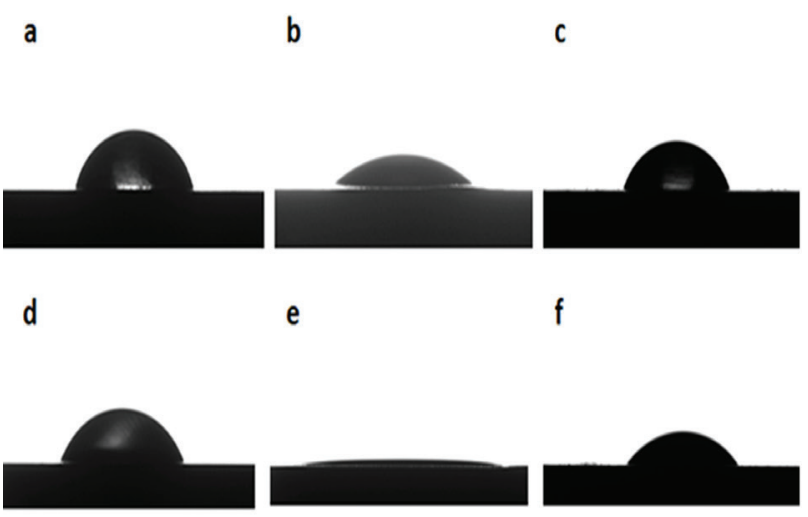

Figure 3 - Images illustrating the contact angle of drops of water $(a, b, c)$ and etyhylene glycol $(d, e, f)$ dispensed on the untreated (YTZP_control - $a, d$ ), on the plasma treated surfaces (YTZP_plasma - b, e), and on the primer treated surface (YTZP primer - $\mathrm{c}, \mathrm{f})$. Note the significant reduction of the contact angle after 16 min of NTP exposure. 
Table 4 - Distribution of failure modes among experimental groups (\%).

\begin{tabular}{|l|cc|}
\hline Groups & $\begin{array}{c}\text { Cohesive } \\
\text { Failure }\end{array}$ & $\begin{array}{c}\text { Mixed } \\
\text { Failure }\end{array}$ \\
\hline YTZP_control & 10 & 90 \\
\hline YTZP_plasma & 38 & 62 \\
\hline YTZP_primer & 27 & 73 \\
\hline
\end{tabular}

\section{DISCUSSION}

The null hypotheses that NTP treatment do not increase the surface energy (1) and the microshear bond strength (3) of zirconia were rejected, while the second null hypothesis that stated that plasma treatment does not increase roughness was accepted.

This is the first study to suggest NTP surface treatment as a non-destructive method to effectively enhance the bond strength of a new formulation of a resin cement (Panavia V5) to Y-TZP surfaces. Modification of the zirconia surface has shown that effective bonding is only achieved with a synergic effect of physical and chemical treatments $[23,34,35]$. Moreover, it is important to consider that some of the physical treatments available, such as airbone-particle abrasion with alumina and tribochemical silica coating, can induce micro-cracks on the Y-TZP surface which might reduce its clinical durability $[11,12]$.

Surface energy of a material can be measured by evaluating the contact angle of liquids and their ability to spread on a certain surface [21]. This method measures the values of dispersive and polar components of SE, clarifying the molecular interactions such as dipole-dipole, hydrogen bond and dispersive forces of London $[24,26]$. Furthermore, enhancing the surface energy results in better wettability, which is key for bonding $[21,36]$.

Recent studies have been reported increase bond strength values between resin cement and zirconia after NTP treatment, although when Ar gas was used [20,24,26,27]. Conversely, the gas used in this study is $\mathrm{O}_{2}$. The presence of the oxygen in the operating gas of the plasma device promotes the formation of active peroxide radicals (R-O-O-), which initiate chemical surface changes even in inert materials such as dense crystalline sintered ceramics [15]. Moreover chemical surface treatment with oxygen plasma removes organic impurities attached to the zirconia surface by breaking $\mathrm{C}-\mathrm{H}$ and $\mathrm{C}-\mathrm{C}$ bonds. As a result, it allows the formation of active peroxide radicals which promote further incorporation of functional groups (C-O- and $\mathrm{C}-\mathrm{OH}$ ) at the material surface $[17,26]$. These functional groups probably were responsible for the increase in surface energy as well as higher values of bond strength [17]. These results were in accordance with previous studies which reported an increase in polar components and in bond strength after plasma surface treatment $[20,25,26]$. Likely, the increase of polar components on the zirconia surface after surface treatment with plasma should be related to enhancing the amount of $\mathrm{O}_{2}$ molecules, which lead to higher SE $[17,20,21,26]$. The surface modification favours the appearance of secondary forces between molecules, such as Van der Waals bonds, which occur between the hydroxyl groups existing in the resin cement and the hydroxyl groups formed on the plasma treated surface [2527]

Regarding the microshear test, NTP surface treatment (YTZP plasma) increased the bond strength when compared to the others groups. This result is probably related to the higher wettability of the zirconia surface after plasma treatment, as well as chemical linking between hydroxyl groups and the resin cement. On the other hand, there was no significant difference in bond strength values between the control group (YTZP control) and the ceramic primer group (YTZP primer). These results are in agreement with former studies [13,37].

The ceramic primer coupling agent used in this study (Clearfil Ceramic Primer, Kuraray Noritake) contains 10-MDP, which bonds to zirconia by physicochemical interaction between zirconium oxide and the polymeric component of the resin cement through formation of the 
Phosphorus-Oxygen-Zirconia (P-O-Zr) chemical bond [38]. The literature showed that the composition of the ceramic primer is essential for suitable performance as a bonding agent, in particular when used without surface treatment $[13,14]$. Authors claiming that the best performing primers are those that mix two distinct molecules such as 6-(4-vinylbenzyl-n-propyl) amino-1,3,5triazine-2,4 dithiol (VBATDT) and 10-MDP [13].

The resin cement used in the present investigation (PV5) is a type of conventional adhesive resin cement without 10-MDP and requires the pretreatment of the tooth substrate with a primer containing this monomer [39]. The present study is the first reporting the bonding effectiveness between PV5 and Y-TZP ceramic after NTP treatment. Although luting resins containing 10-MDP have demonstrated good bonding performance in vitro studies $[34,40,41]$, studies demonstrated that this monomer appeared hydrolytically unstable in water [42], and an acidic monomer causes a low degree of conversion and weak bonding compared to Panavia V5, which does not contain 10-MDP in the cement [28]. Analysis of fractured interfacial zone shows a predominance of mixed failures for all experimental groups, which might be related to efficient bond strength. One of the limitations of this study was that the effects of thermocycling and long-term storage on $\mu$ SBS were not evaluated. Therefore, further studies are necessary to evaluate the long-term stability of luting protocols with chemistry of PV5.

Roughness parameters are useful for quantifying the microstructure of ceramic surfaces to develop structure property relationships. Among those parameters, Ra (roughness average), which represents the mathematical average height of roughness irregularities measured from a mean line within the sampling length, is the most commonly reported roughness parameter in the dental literature [15]. It was expected that a rougher surface would have provided an additional micromechanical retentive pattern due to the increase in the surface area $[15,16]$. However, the results of this study showed a weak correlation between roughness and bond strength since the roughness values obtained in (YTZP plasma) were statistically similar to that measured for the control group (YTZP control) and ceramic primer group (YTZP_primer). Such results agree with previous studies which not detect significant correlation between roughness and bond strength $[43,44]$. Thus, the chemical forces/alterations that result from plasma surface treatment should be responsible for the increasing bonding values between resin cement and zirconia.

\section{CONCLUSION}

Within the limitations of this study, we concluded that non-thermal plasma might be an alternative surface treatment of zirconia samples prior cementation hence it improved bond strength and provided higher surface energy without affecting surface roughness.

\section{ACKNOWLEDGMENTS}

The authors thank KOTA sales repesentative of Kuraray Noritake Dental for supporting this work through generous donation of resin cements.

FUNDING: This work was supported by State of Sao Paulo Research Foundation (Grant No 2015/13571-1 and 2016/13117-1). The authors declare that they have no conflict of interest.

\section{REFERENCES}

1. Miyazaki T, Matsumura TNH, Ban S, Kobayashi T.Current status of zirconia restoration. Prosthodont. 2013;57:236-61.

2. Garcia Fonseca R, de Oliveira Abi-Rached F, dos Santos Nunes Reis JM, Rambaldi E, Baldissara P.Effect of particle size on the flexural strength and phase transformation of an airborne-particle abraded yttria-stabilized tetragonal zirconia polycrystal ceramic. J Prosthet Dent. 2013 Dec;110(6):5104. doi: 101016/j.prosdent.2013.07.007. Epub 2013 0ct29.

3. Pereira G, Amaral M, Cesar PF, Bottino MC, Kleverlaan CJ, Valandro LF. Effect of low-temperature aging on the mechanical behavior of ground Y-TZP.J Mech Behav Biomed Mater. 2015 May;45:183-92. doi: 10.1016/j. jmbbm.2014.12.009.

4. Vanderlei A, Bottino MA, Valandro LF. Evaluation of resin bond strength to yttria-stabilized tetragonal zirconia and framework marginal fit: comparison of different surface conditionings. Oper Dent. 2014;39:50-63. 
5. DruckCC, Pozzobon JL, Callegari GL, Dorneles LS, Valandro LF. Adhesion to Y-TZP ceramic: Study of silica nanofilm coating on the surface of Y-TZP. J Biomed Mater Res B Appl Biomater. 2015 Jan;103(1):143-50. doi: 10.1002/ jbm.b.33184.

6. Khan AA, Al Kheraif AAA, Jamaluddin S, Elsharawy M, Divakar DD. Recent trends in surface treatment methods for bonding composite cement to zirconia: a review. J Adhes Dent. 2017;19(1):7-19. doi: 10.3290/j.jad.a37720

7. Moradabadi A, Roudsari SE, Yekta BE, Rahbar N. Effects of surface treatment on bond strength between dental resin agent and zirconia ceramic. Mater Sci Eng C Mater Biol Appl. 2014 Jan 1;34:311-7. doi:10.1016/j. msec.2013.09.015

8. Hallmann L, Ulmer P, Lehmann F, Wille S, Polonskyi 0, Johannes M, et al. Effect of surface modifications on the bond strength of zirconia ceramic with resin cement resin. Dent Mater. 2016 May;32(5):631-9. doi:10.1016/j. dental.2016.02.001.

9. Aras WMF, Barroso JSM, Blay A, Rodrigues JA, Cassoni A. Er,Cr:YSGG laser irradiation influence on Y-TZP bond strength to resin cement. Ceram Int 2016:42: 13790-5

10. Alves M, Campos F, Bergoli CD, Bottino MA, Özcan M, Souza R. Effect of adhesive cementation strategies on the bonding of Y-TZP to human dentin Oper Dent. 2016 May-Jun;41(3):276-83. doi: 10.2341/15-052-L.

11. Chevalier J. What future for zirconia as a biomaterial? Biomaterials. 2006;27(4):535-43.

12. Chintapalli RK, Marro FG, Jimenez-Pique E, Anglada M. Phase transformation and subsurface damage in 3Y-TZP after sandblasting. Dent Mater. 2013 May;29(5):566-72. doi:10.1016/j.dental.2013.03.005.

13. Dias de Souza GM, Thompson VP, Braga RR. Effect of metal primers on microtensile bond strength between zirconia and resin cements. J Prosthet Dent. 2011;105:296-303.

14. Amaral M, Belli R, Cesar PF, Valandro LF, Petschelt A, Lohbauer U.The potential of novel primers and universal adhesives to bond to zirconia. $J$ Dent. 2014 Jan;42(1):90-8. doi: 10.1016/j.jdent.2013.

15. Cavalcanti AN, Pilecki P, Foxton RM, Watson TF, Oliveira MT, Gianinni M, Marchi GM. Evaluation of the surface roughness and morphologic features of YTZP ceramics after different surface treatments. Photomed Laser Surg. 2009 Jun;27(3):473-9. doi: 10.1089/pho.2008.2293.

16. Silva BTF, Cesar PF, Freitas PM, Palma-Dibb RG, Matos AB. Threedimensional profilometric assessment of Er:YAG laser irradiated unsintered zirconia. J Mater Sci 2016;51:7266-75.

17. Vechiato Filho AJ, dos Santos DM, Goiato MC, de Medeiros RA, Moreno A, Bonatto Lda R, Rangel EC. Surface characterization of lithium disilicate ceramic after nonthermal plasma treatment. J Prosthet Dent. 2014 Nov;112(5):1156-63. doi: 10.1016/.jprosdent.2014.02.021.

18. dos Santos DM, Vechiato-Filho AJ, da Silva EV, Goiato MC, Cesar PF, Rangel $\mathrm{EC}$, da Cruz NC. Aging effect of atmospheric air on zirconia surfaces treated by nonthermal plasma. J Adhes Dent. 2015 Aug;17(5):413-9. doi:10.3290/j. jad.a35011.

19. Duan Y,Huang C, Yu QS. Cold plasma brush generated at atmospheric pressure. Rev Sci Instrum. 2007 Jan;78(1):015104.

20. Silva NR, Coelho PG, Valverde GB, Becker K, Ihrke R, Quade A, Thompson VP.Surface characterization of Ti and Y-TZP following non-thermal plasma exposure. J Biomed Mater Res B Appl Biomater.20110ct;99(1):199-206. doi: 10.1002/jbm.b.31887.

21. Lopes BB, Ayres APA, Lopes LB, Negreiros WM, Giannini M. The effect of atmospheric plasma treatment of dental zirconia ceramics on the contact angle of water. Appl Adhes Sci 2014;2:17. doi.org/10.1186/2196-4351-2-17.
22. Han GJ, Chung SN, Chun BH, Kim CK, Oh KH, Cho BH. Effect of the applied power of atmospheric pressure plasma on the adhesion of composite resin to dental ceramic. J Adhes Dent. 2012 Aug;14(5):461-9. doi: 10.3290/j.jad. a25688.

23. Hallmann L, Ulmer P, Wille S, Polonskyi O, Köbel S, Trottenberg T. Effect of surface treatments on the properties and morphological change of dental zirconia. J J Prosthet Dent. 2016 Mar;115(3):341-9. doi: 10.1016/j. prosdent.2015.09.007.

24. Vechiato-Filho AJ, Matos A0, Landers R, Goiato MC, Rangel EC, De Souza GM6, et al. Surface analysis and shear bond strength of zirconia on resin cements after non-thermal plasma treatment and/or primer application for metallic alloys. Mater Sci Eng C Mater Biol Appl. 2017 Mar 1;72:284-292. doi: 10.1016/j.msec.2016.11.033.

25. Wu CC, Wei CK, Ho CC, Ding SJ. Enhanced hydrophilicity and biocompatibility of dental zirconia ceramics by oxygen plasma treatment. Materials (Basel). 2015 Feb 16;8(2):684-699. doi: 10.3390/ma8020684..

26. Valverde GB, Coelho PG, Janal MN, Lorenzoni FC, Carvalho RM, Thompson VP, et al. Surface characterisation and bonding of Y-TZP following non-thermal plasma treatment. J Dent. 2013 Jan;41(1):51-9. doi: 10.1016/j.jdent.2012.10.002.

27. Ito Y,Okawa T, Fukumoto T, Tsurumi A, Tatsuta M, Fujii T, et al. Influence of atmospheric pressure low-temperature plasma treatment on the shear bond strength between zirconia and resin cement. JProsthodont Res. 2016 Oct;60(4):289-293. doi:10.1016/j.jpor.2016.02.001.

28. Tagami A, Takahashi R, Nikaido T, Tagami J. The effect of curing conditions on the dentin bond strength of two dual-cure resin cements. J Prosthodont Res. 2017;61:412-418.

29. Rohr N, Fischer N. Tooth surface treatment strategies for adhesive cementation. J Adv Prosthodont. 2017;9:85-92.

30. Vizir A1, Oks EM, Salvadori MC, Teixeira FS, Brown IG. Small plasma source for materials application. . Rev Sci Instrum. 2007 Aug;78(8):086103.

31. Owens DK, Wendt RC. Estimation of surface free energy of polymers. J Appl Polym Scienc 1969;13:1741-8.

32. Sabrah AH, Cook NB, Luangruangrong P, Hara AT, Bottino MC. Full-contour Y-TZP ceramic surface roughness effect on synthetic hydroxyapatite wear. Dent Mater. 2013 Jun;29(6):666-73. doi:10.1016/j.dental.2013.03.008.

33. Shimaoka AM, Andrade AP,Cardoso MV, De Carvalho RRC. The importance of adhesive area delimitation in a microshear bond strength experimental design. J Adhes Dent. 2011;13:307-314.

34. Bottino MA, Bergoli C, Lima EG, Marocho SM, Souza RO, Valandro LF. Bonding of Y-TZP to dentin: effects of Y-TZP surface conditioning, resin cement type, and aging. Oper Dent. 2014 May-Jun;39(3):291-300. doi: 10.2341/12-235-L

35. Nishigawa G, Maruo Y, Irie M, Maeda N, Yoshihara K, Nagaoka N, Matsumoto T, Minagi S. Various effects of sandblasting of dental restorative materials. PLoS One. 2016 Jan 14;11(1):e0147077. doi:10.1371/journal.pone.0147077. eCollection 2016 .

36. Noro A1, Kameyama A, Haruyama A, Takahashi T. Influence of hydrophilic pre-treatment on resin bonding to zirconia ceramics. Bull Tokyo Dent Coll. 2015;56(1):33-9. doi: 10.2209/tdcpublication.56.33.

37. De Souza GM, Hennig D, Aggarwal A, Tam LE. The use of MDP-based materials for bonding to zirconia. J Prosthet Dent. 2014;112:895-902.

38. Chen L, Suh Bl, Brown D, Chen X. Bonding of primed zirconia ceramics: evidence of chemical bonding and improved bond strengths. Am J Dent.2012;25:103-8 
39. Higashi M, Matsumoto M, Kawaguchi A, Miura J, Minamino T, Kabetani T, et al. Bonding effectiveness of self-adhesive and conventional-type adhesive resin cements to CAD/CAM resin blocks. Part 1: Effects of sandblasting and silanization. Dent Mater J. 2016;35(1):21-8. doi:10.4012/dmj.2015-234..

40. Furuichi T, Takamizawa T, Tsujimoto A, Miyazaki M, Barkmeier WW, Latta MA. Mechanical properties and sliding-impact wear resistance of self-adhesive resin cements. Oper Dent. 2016 May-Jun;41(3):E83-92. doi: 10.2341/15-033-L.

41. Stefani A, Brito RB Jr, Kina S, Andrade OS, Ambrosano GM, Carvalho AA, et al. Bond strength of resin cements to zirconia ceramic using adhesive primers. J Prosthodont. 2016 Jul;25(5):380-5. doi: 10.1111/jopr.12334
42. Muller JA, Rohr N, Fischer J. Evaluation of ISO 4049: water sorption and water solubility of resin cements. Eur J Oral Sci. 2017;125:141-150.

43. de Oyagüe RC1, Monticelli F, Toledano M, Osorio E, Ferrari M, Osorio R. Influence of surface treatments and resin cement selection on bonding to densely-sintered zirconium-oxide ceramic. Dent Mater. 2009 Feb;25(2):1729. doi: 10.1016/.jdental.2008.05.012.

44. Abi-Rached F0, Martins SB, Almeida-Júnior AA, Adabo GL, Góes MS, Fonseca RG. Air abrasion before and/or after zirconia sintering: surface characterization, flexural strength, and resin cement bond strength. Oper Dent. 2015 Mar-Apr;40(2):E66-75. doi: 10.2341/14-013-LR1.

\section{Adriana Bona Matos}

\section{(Corresponding address)}

School of Dentistry - University of Sao Paulo

Operative Dentstry Departament

Av. Prof. Lineu Prestes, 2227, Cidade Universitária, 05508-

000 São Paulo, SP, Brazil

Date submitted: 2018 Mar 01

e-mail: bona@usp.br 